Article

\title{
Non-Adaptive Behavior in the Face of Climate Change: First Insights from a Behavioral Perspective Based on a Case Study among Firm Managers in Alpine Austria
}

\author{
Ulrike Meinel $^{1,2, *}$ and Karl-Michael Höferl ${ }^{2}$ \\ 1 alpS-Center for Climate Change Adaptation, Grabenweg 68, 6020 Innsbruck, Austria \\ 2 Institute of Geography, University of Innsbruck, Innrain 52f, 6020 Innsbruck, Austria; \\ karl-michael.hoeferl@uibk.ac.at \\ * Correspondence: meinel@alps-gmbh.com; Tel.: +43-(0)681-84154095
}

Received: 1 May 2017; Accepted: 25 June 2017; Published: 28 June 2017

\begin{abstract}
Although climate change can induce large-scale impacts on industrial supply chain networks, first empirical studies suggest that adaptation to climate change is only slowly emerging as a management topic in firms. The present study examines why managers often do not engage their firms in adaptations to climate change. Thereby the study focuses, in particular, on the lack of strategic adaptation, which we define as anticipatory and target-oriented action with the purpose of increasing resilience to climate change. In order to investigate causes of lacking strategic adaptation in firms, the study employs a behavioral perspective based on the reasoned action approach. Thus, the study examines how barriers and motivational factors jointly shape the non-adaptive behavior of firm managers. Such causes of non-adaptive behavior are examined by comparing different classes of non-adaptors based on a case study in the manufacturing industry of the Austrian state of Tyrol. The obtained results underline recent criticism on barrier-centered analyses of non-adaptation by demonstrating the importance of motivational factors. Moreover, results point to the changeable nature of the identified causes of non-adaptive behavior by clarifying interactions between them and by suggesting influences from background factors.
\end{abstract}

Keywords: climate change adaptation; manufacturing industry; behavioral perspective; actor-centered approach; barriers; motivational factors

\section{Introduction}

In scientific debates, the critical importance of climate change adaptation in industry has repeatedly been emphasized [1-4]. For example, various 'climatically reinforced risks' have been pointed out to manufacturing firms [3], such as transport interruptions, supplier drop-outs, risks of electricity and water supply, or increasing prices for renewable raw materials [3]. However, a lack of strategic adaptations by individual firms may not only affect the resilience of these firms, but can also put at risk other businesses in the supply chain network. Additionally, ecological and socio-economic aspects of sustainable development can be affected [5-7]. However, first empirical studies have shown that strategic adaptations only occur in a minority of firms [8,9]. Existing adaptations in the private sector would instead often emerge non-strategically as 'hidden adaptations' [10-12] respectively as unconscious co-benefits of measures motivated by other strategic targets $[2,13]$.

Although the body of literature on causes of non-adaptation is growing, analytical lenses in this field of research have been described as rare and dominated by a 'problem solving' lens [14] (p. 1011) focusing on barriers. This barrier-centered perspective has recently been criticized for being at risk of itemizing and reifying barriers as static entities [15]. Thus, according to recent literature 
reviews, barrier-centered studies would mostly examine which barriers exist, yet would neglect the question of how barriers emerge in response to political, communicative or cognitive processes $[15,16]$. Moreover, studies have shown that even if barriers are 'removed', a lack of strategic adaptations often persists [16].

Based on this background, the present study represents an initial attempt to open the black box of actors and their intentions from a behavioral perspective. Building upon the reasoned action approach as developed in psychology $[17,18]$, the authors investigate how barriers and motivational factors jointly shape non-adaptive behavior of firm managers. For this purpose, the authors compared the behavior of firm managers belonging to different classes of non-adaptors based on a case study in the manufacturing industry of the Austrian state of Tyrol. Thus, a research setting was chosen that has been described as particularly climate-sensitive due to its alpine environment [3].

Notwithstanding the fact that managers may partially engage their firms in strategic adaptations, the study exclusively examines the behavior of managers who have not taken respective initial steps. In the present study, these managers are termed non-adaptors and underlying behavior is called non-adaptive behavior.

When examining causes of non-adaptive behavior, the study presumes that managers-at least CEOs-are in principle able to engage their firms in strategic adaptations by putting the topic on the agenda if they intend to do so. Thus, the study conceives strategic adaptations as any purposive and anticipatory adaptive action, irrespectively of whether respective actions are sufficiently informed and allow an effective increase of resilience.

Initially, the study depicts the state of research on the economic, ecological and social relevance of strategic adaptations in manufacturing firms and on explanations for lacking strategic adaptations. Subsequently, the applied behavioral perspective is outlined in theoretical terms. Afterwards, a methodology for comparing causes of non-adaptive behavior across different classes of non-adaptors is developed. Then, the design of the case study and case study results are depicted. Finally, emerging insights into the causality of non-adaptive behavior are condensed, implications for adaptation research are discussed, and emerging research gaps are outlined.

\section{The Importance of Strategic Adaptation in Manufacturing Firms and Causes for Lacking Strategic Adaptation-The State of Research}

Recent studies suggest that lacking strategic adaptation may not only increase a firm's own vulnerability $[2,3,19]$, but may influence various aspects of sustainable development. In this regard, studies have stressed that insufficient adaptation of firms may induce domino effects in supply chains if hazards occur $[3,5,6,20]$. Thus, direct or indirect impacts of climate change on one firm (e.g., production halt due to extreme weather events, or losses due to changed legislation) may critically affect customers as well as suppliers [3]. For example, respective domino effects occurred in 2011 after floods in Thailand when the supply of basic components for automobile and electronics industries was interrupted [21]. Furthermore, ecological risks have been explored, such as potential impacts of climatically induced hazards on the safety of production processes, particularly if high risk technologies are applied (e.g., in chemical industries) [22,23]. Finally, studies have discussed socioeconomic risks of insufficient adaptations in firms. Thus, it has been argued that losses due to physical damages at production sites or due to supply interruptions can induce impacts on local employment and on insurance systems [7,21]. As lacking strategic adaptation in manufacturing firms may thus affect the resilience of firms as well as sustainable development on broader societal scales, causes for its lack come into focus.

Although explanations of non-adaptation have increasingly been developed, respective studies have been described as lacking analytical diversity. Thus, literature reviews have emphasized that a 'problem solving lens [14] (p. 1011) focusing on barriers would dominate the most of respective research $[14,16]$. In fact, various barriers to adaptation-defined as 'factors and conditions which hamper the process of developing and implementing climate change adaptations' [15] — have been revealed, including specific barriers for firms, as summarized in Table 1. 
Table 1. Barriers to climate change adaptation in firms.

\begin{tabular}{ll}
\hline Barriers & Sources \\
\hline Lacking knowledge and uncertainty about future impacts of climate change & {$[22,24,25]$} \\
Lacking financial and personnel resources & {$[22,24,25]$} \\
Lacking competitive advantages of climate change adaptation, economic limitations & {$[22,24,25]$} \\
Lacking incentives from the political and financial markets environment & {$[22,24,26]$} \\
Lacking inspiration by good practices & {$[22]$} \\
Multiple pressures competing for managerial attention & {$[2]$} \\
Lacking managerial capabilities to deal with climate change & {$[2,24,27,28]$} \\
Conservatism in organizations & {$[2]$} \\
\hline
\end{tabular}

Moreover, in an alternative, sociological strand of research, systemic barriers to adaptation have been investigated. Such studies have, for example, explored dependencies of successful adaptations on the interplay of different levels of society (e.g., of individuals, corporate actors and governments) [29]. Moreover, it has been suggested that system properties, such as lacking structures for cooperation and learning, may affect the resilience of social-ecological systems [30-32]. However, as the present study adopts an actor-centered perspective on non-adaptation, such systemic barriers to adaptation are not further discussed below.

In contrast to barrier-centered analyses, some newly emerging, actor-centered studies suggest that a focus on barriers may veil the role of actors, their strategies and motivation, and may subsequently suggest inadequate recommendations how adaptations might be supported [16]. In this sense, it has been suggested that the development of barriers depends on political, communicative and cognitive processes [16,33]. Actor-centered studies have moreover investigated how different framings [34] and discourses [35] may influence motivation to adapt. Finally, perceptions of costs and benefits, beliefs and emotions of actors have been analyzed as potential explanations for non-adaptive behavior [16,36,37].

\section{Introducing Behavioral Theory into the Analysis of Non-Adaptation}

Building upon the outlined critique of reified conceptions of barriers, the authors argue that a more comprehensive understanding of non-adaptive behavior requires a combined analysis of barriers and of motivational factors. In this sense, the authors refer to the 'reasoned action approach' developed by Fishbein and Ajzen $[17,18]$ as a frequently applied approach of environmental psychology [38,39]. Building upon the reasoned action approach, which has formerly been called theory of planned behavior' [18], the authors assume that non-adaptive behavior can be traced back

- $\quad$ to non-motivational factors, thus lacking skills and abilities as well as lacking requisite environmental factors (i.e., factors commonly referred to as barriers)

- to motivational factors, thus behavioral beliefs (i.e., anticipated costs and benefits of the behavior), control beliefs (i.e., beliefs regarding the capability to successfully conduct the behavior under consideration of barriers and supportive factors), and normative beliefs regarding the behavior; or

- $\quad$ to interactions of non-motivational factors and motivational factors $[17,18]$

Regarding respective interactions, the reasoned action approach particularly refers to the influence barriers exert on the content of control beliefs [17]. Moreover, it has been assumed that barriers pose limits to the potential effects of motivational factors because motivation 'can find expression in behavior only if [ . . ] the person can decide at will to perform or not perform the behavior' [17,18]. In a slight extension of the depicted approach, the authors vice versa suggest that motivational factors can also mediate the influence of barriers as strong motivation may induce action despite barriers.

Importantly, the reasoned action approach also integrates background factors as further aspects into behavioral analysis: individual background factors (e.g., personality, values, or general attitudes), social background factors (e.g., culture or education), and informational background factors 
(e.g., knowledge and media). These aspects are supposed to affect behavior indirectly by influencing the described, more 'immediate' motivational factors [17].

Based on the outlined considerations, Figure 1 depicts barriers, motivational factors and their interactions within a model of non-adaptive behavior.

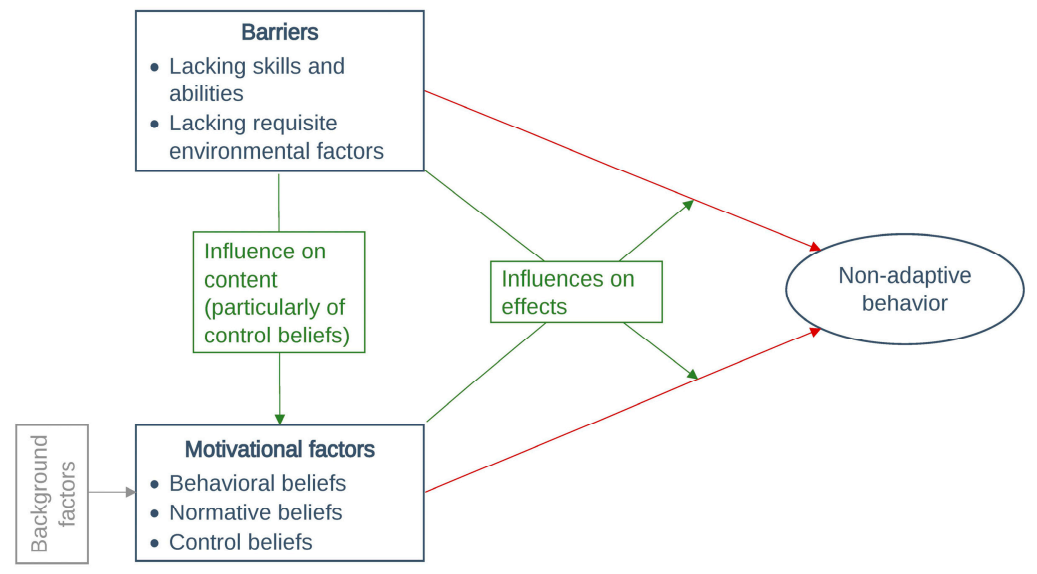

Figure 1. Model of non-adaptive behavior in a variation of the reasoned action model by Fishbein and Ajzen [17]. Appendix A provides an overview of differences between the applied model and the original reasoned action model.

It may be noted that by focusing on psychological explanations of non-adaptive behavior among firm managers, the study restricts its explanatory focus to the individual level. This perspective contrasts more aggregated approaches, such as the behavioral theory of the firm, which concentrates on corporate decision-making processes as determinants of firm behavior [40,41]. However, as the latter approach relies on generalized assumptions about individual behavior, the present analysis might be considered as a preparatory step for respective, more aggregated perspectives on the causality of lacking strategic adaptation in firms.

\section{Identifying Causes of Non-Adaptive Behavior across Classes of Non-Adaptors}

Due to the infant state of behavioral research into non-adaptation, the authors initially examined which factors-and which interactions of factors-can cause non-adaptive behavior. In order to operationalize non-adaptive behavior of managers, the authors employed corporate decisions of firms as a proxy. Although this operationalization neglects the complexity of corporate decision-making processes in firms [40,41], it may represent a way of approaching reality at least when focusing on CEOs [42].

Methodologically, the study examines causes of non-adaptive behavior by comparing different classes of non-adaptors. The classes were distinguished by crossing two indicators, which could be calculated based on survey data: first, the actual implementation of strategic adaptations and second, the perceived relevance of barriers (see Section 5.2.1 and Appendix B regarding the operationalization of these aspects in the survey). Figure 2 depicts the conceptualized classes of (non-)adaptors.

Figure 2 clarifies that classes of non-adaptors and of proactive adaptors (i.e., of 'incremental' and 'front-runner' adaptors) can be conceived. However, corresponding to the aim of examining the range of causes of non-adaptive behavior, the study exclusively compares classes of non-adaptors. 


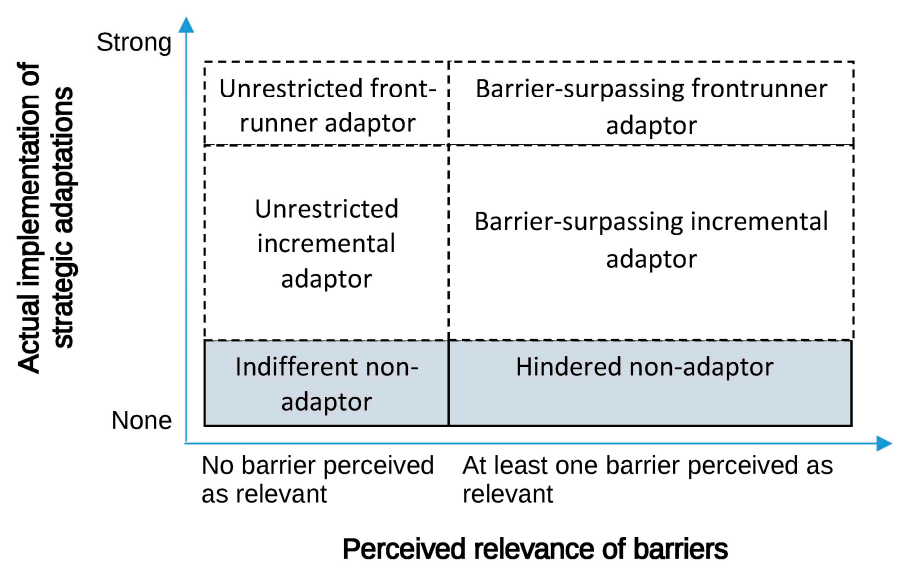

Figure 2. Distinguished classes of (non-)adaptors.

Classifying non-adaptors thereby neglects that behavior of an actor may change over time and that behavior may depend on circumstances and on the adaptive action in question. Thus, various forms of behavior may occur across individuals and with regard to actions of one individual across time. While reality may thus consist of a changing spectrum of behavior, this complexity is simplified in the classification, which allows comparative analysis.

The adopted classification may particularly suit investigations into the causality of non-adaptive behavior as different alignments of barriers and motivational factors can be presumed across classes: Indifferent non-adaptors are conceived as managers who completely abstain from engaging their firms in strategic adaptations while not perceiving any barriers to adaptation as relevant. Consequently, based on the behavioral model (Figure 1), motivational factors have to be considered as the prevailing cause of non-adaptive behavior in this group.

Hindered non-adaptors similarly abstain from engaging their firms in strategic adaptations, yet perceive one or more barriers to adaptation as relevant. Managers belonging to this class of non-adaptors may include motivated actors, who would initiate and implement strategic adaptations if barriers are removed. However, even in the absence of barriers, some managers in this group may still not respectively act due to a lack of motivation. Thus, barriers, motivational factors and interactions between these aspects can represent causes of non-adaptive behavior among 'hindered non-adaptors'.

Based on these characterizations, Table 2 summarizes which causes of non-adaptive behavior are identifiable across classes of non-adaptors.

Table 2. Identifiable causes of non-adaptive behavior across classes of non-adaptors.

\begin{tabular}{lll}
\hline Class of Non-Adaptors & \multicolumn{2}{l}{ Identifiable Causes of Non-Adaptive Behavior } \\
\hline Indifferent non-adaptors & $\bullet$ & Motivational factors \\
\hline & $\bullet$ & Barriers \\
Hindered non-adaptors & $\bullet$ & Motivational factors \\
& $\bullet$ & Interactions between barriers and \\
& & motivational factors \\
\hline
\end{tabular}

As suggested in Section 3, motivational factors can themselves be subject to influences of various background factors (see Figure 1). However, the question what effects specific background factors have and how their role differs between classes of non-adaptors remains beyond the scope of the present study. 


\section{Case Study Design}

Based on the described theoretical and methodological assumptions, the authors conducted a case study in the alpine Austrian state of Tyrol.

\subsection{Research Setting}

When investigating causes of non-adaptive behavior, Tyrol as an alpine region represents a particularly climate-sensitive research setting. Thus, similar to other mountainous regions, Tyrol is subject to a particularly intense rise of average temperatures, which occurs nearly three times as strong as at global average [43]. As a consequence, risks of natural mountain hazards, such as debris flows, rockfall and hang slides, are increased [44] and induce subsequent risks for manufacturing firms, such as physical risks for buildings or transportation risks [3]. Therefore, it may be assumed that strategic adaptations in firms are of particular relevance in this setting. In turn, this setting may have an impact on survey results as if perceived, comparatively high climate risks may influence motivation to adapt [3].

\subsection{Methodology of the Case Study}

In order to examine barriers, motivational factors, and interactions of these aspects, the authors combined a quantitative firm survey with semi-structured interviews with firm managers. Thereby the initial classification of firms was conducted based on survey data. Perceptions of barriers, too, were investigated in the survey. In order to ensure that relevant barriers were not ignored, survey results were inductively extended based on interviews. Motivational factors and their interactions with barriers are more difficult to reveal in a survey due to scarce research on motivational factors and interactions (see Section 2) and due to the subtle nature of these aspects. Thus, motivational factors and interactions were exclusively investigated in interviews.

Quantitative and qualitative methods were thus combined in response to problem-specific requirements emerging from the different states of research on barriers and motivational factors and from the differently tangible nature of these aspects. However, choosing methods in line with such scientific and ontological characteristics of the aspects in question implies a consecutive use of methods. Nonetheless, obtained results may promote a leveling of data regarding all focused aspects. Thus, inductively generated insights into motivational factors may support future behaviorist research designs, which exclusively employ deductive analyses of barriers and motivational factors, or which integrate deductive and inductive approaches for analyzing all of the focused aspects.

\subsubsection{Quantitative Phase}

In cooperation with the Tyrolean Chamber of Commerce, the survey was sent to managers of all manufacturing firms in Tyrol with at least five employees. In order to reach managers having maximum influence on strategic decisions linked to environmental issues, the survey addressed either CEOs or, in case of larger firms, environmental managers. In total, 1871 firms were contacted, out of which 102 firms replied. Thus, the response rate (5\%) was low compared to average response rates of surveys in organizations [45]. In order to improve the response rate after the initial mailing of the questionnaire, the survey had also been promoted online on the homepage of the Chamber of Commerce and within the regular newsletter of the Chamber to its members. The fact that no reward, apart from conveying study results, was offered to participants might have been one reason for the low response rate. Another reason might be frequently occurring perceptions among managers regarding a low relevance of the topic for their business success (see Section 6).

Regarding responsibilities, the Chamber of Commerce distributed the survey and was in turn provided by the authors with results of the analysis. In contrast, the authors were responsible for conceptualizing the surveyed barriers and for analyzing survey results. As the separation of responsibilities was adhered to, the cooperation did not influence the scientific work steps. 
Figure 3 depicts the sectoral distribution of manufacturing firms in Tyrol as compared to the survey. As the sample is a good representation of the sectoral distribution in Tyrol, no ex-post weighting of survey results was conducted.
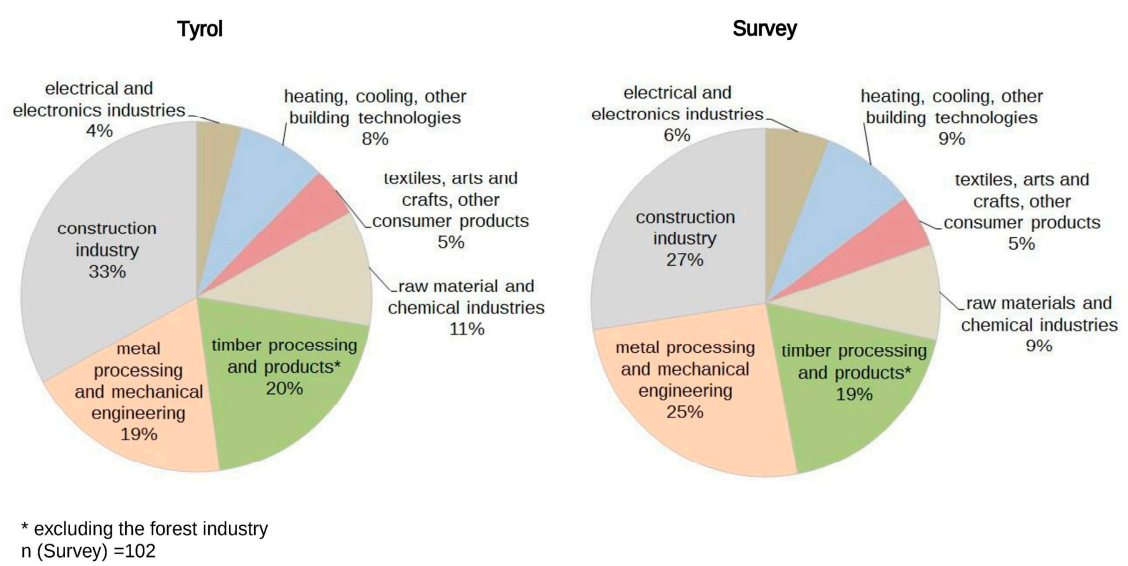
$\mathrm{n}$ (Survey) $=102$

Figure 3. Sectoral distribution of manufacturing firms in Tyrol compared to the survey (\% of firms). Calculations conducted by the authors, based on Tyrolean Chamber of Commerce [46].

Based on existing literature (see Section 2), perceptions of six barriers were surveyed. In the survey, respondents could indicate to perceive suggested barriers as 'very small', 'somewhat small', 'somewhat tall' or 'very tall'. Moreover, one open question allowed respondents to indicate other barriers, if perceived. Table 3 depicts how barriers suggested in literature were operationalized in the survey.

Table 3. Barriers described in literature and their operationalization in the survey.

\begin{tabular}{ll}
\hline Barriers Described in Literature & Operationalization of the Barrier in the Survey \\
\hline $\begin{array}{l}\text { Lacking knowledge and uncertainty about future impacts of } \\
\text { climate change }\end{array}$ & $\begin{array}{l}\text { Lacking information on expectable climatic impacts at } \\
\text { company locations and in the supply chain network }\end{array}$ \\
\hline Lacking financial and personnel resources & Lack of personnel, time and finances \\
\hline $\begin{array}{l}\text { Lacking competitive advantages of climate change } \\
\text { adaptation, economic limitations }\end{array}$ & $\begin{array}{l}\text { Lacking effects of CCA on reputation among customers } \\
\text { and business partners }\end{array}$ \\
\hline $\begin{array}{l}\text { Lacking incentives from the political and financial } \\
\text { markets environment }\end{array}$ & $\begin{array}{l}\text { Lacking effects of CCA on reputation among investors and } \\
\text { capital providers }\end{array}$ \\
\hline Lacking inspiration by good practices & Lack of good practices and entrepreneurial success stories \\
\hline Multiple pressures competing for managerial attention & $\begin{array}{l}\text { Lacking relevance of the topic for everyday business } \\
\text { operations }\end{array}$ \\
\hline Lacking managerial capabilities to deal with climate change & $*$ \\
\hline Conservatism in organizations & $*$ \\
\hline $\begin{array}{l}* \text { Barrier not operationalized in the survey due to expected response effects among interrogated firm managers } \\
\text { regarding social desirability; CCA is Climate change adaptation. }\end{array}$
\end{tabular}

Analytically, relative frequency distributions were employed in order to depict how barriers were perceived by responding managers. Quantitative data were analyzed with the program SPSS by the authors.

In order to identify managers belonging to the distinguished classes of non-adaptors (see Figure 2), predefined criteria referring to perceptions of barriers and to the implementation of strategic adaptations were used. Thus, an a priori segmentation approach [47] was employed, which enabled an analysis of causes of non-adaptive behavior based on presumed characteristics of actors belonging 
to the distinguished classes (see Table 2 and Section 4). Appendix B describes in detail how the segmentation of non-adaptors was operationalized in the survey and calculated based on obtained data.

\subsubsection{Qualitative Phase}

Interviews were conducted with managers who could be assigned to the different classes of non-adaptors based on survey results. A total of 16 managers were interviewed of which 8 belonged respectively to the classes of 'hindered non-adaptors' and of 'indifferent non-adaptors'.

Interviews served two purposes: first, more extended insights into barriers to adaptation were generated. In order to activate further thought about barriers to adaptation among interviewees, the authors mentioned potential impacts of climate change on supply chains as discussed in literature (see Section 1 and [3]).

Second, interviews investigated motivational factors and their interplay with barriers. These aspects were jointly examined based on one guiding question (see Table 4).

Table 4. Guiding questions for analyzing motivational factors and their interactions with barriers.

\begin{tabular}{ccc}
\hline Class of Non-Adaptors & \multicolumn{2}{c}{ Guiding Question } \\
\hline Indifferent non-adaptors & $\bullet$ & $\begin{array}{l}\text { Why were strategic adaptations not implemented } \\
\text { although no barriers were perceived? }\end{array}$ \\
\hline Hindered non-adaptors & $\bullet$ & $\begin{array}{l}\text { Why were strategic adaptations not implemented } \\
\text { despite perceived barriers? }\end{array}$ \\
\hline
\end{tabular}

In order to interview managers disposing of maximum influence on strategic decisions, the authors originally requested CEOs for interviews. As it was not possible to reach sufficient interviewees from the focused classes in this way, the authors yet broadened the scope of potential interview partners. Finally, 12 interviewees were CEOs and four interviewees were deputy CEOs. Corresponding to the size structure of Tyrolean industrial companies [48], interviewees belonged to 14 small and medium-sized enterprises ( $<250$ employees; according to definitions of the European Commission) and to two large enterprises ( $>250$ employees). Interviews were conducted in the form of telephone interviews. Results were analyzed by the authors based on a content analysis of interviews, without using specific software for qualitative analysis.

\section{Case Study Results}

The following sections present case study results on causes of non-adaptive behavior by contrasting the distinguished classes of non-adaptors.

\subsection{Causes of Non-Adaptive Behavior among 'Hindered Non-Adaptors'}

49 respondents ( $48 \%$ of all survey respondents) matched the criteria of 'hindered non-adaptors' (see Section 4). Below, causes of non-adaptive behavior emerging in this group are analyzed.

\subsubsection{Perceived Barriers}

Based on survey results, Figure 4 depicts perceptions of barriers in the class of 'hindered non-adaptors'.

Figure 4 shows that 'lacking relevance of the topic for everyday business operations', a 'lack of personnel, time and finances', and 'lacking effects of climate change adaptation on reputation among customers and business partners' were perceived as most relevant barriers. These barriers were each considered as either 'somewhat tall' or 'very tall' by more than two thirds of respondents belonging to this group.

Interestingly, 'lacking information' represents the less perceived barrier in this group (and in the whole sample), despite being depicted as one of the most important barriers to adaptation in 
literature $[24,25,49,50]$. Furthermore, it was noted that although other barriers could have been indicated, none were additionally stated by survey respondents.

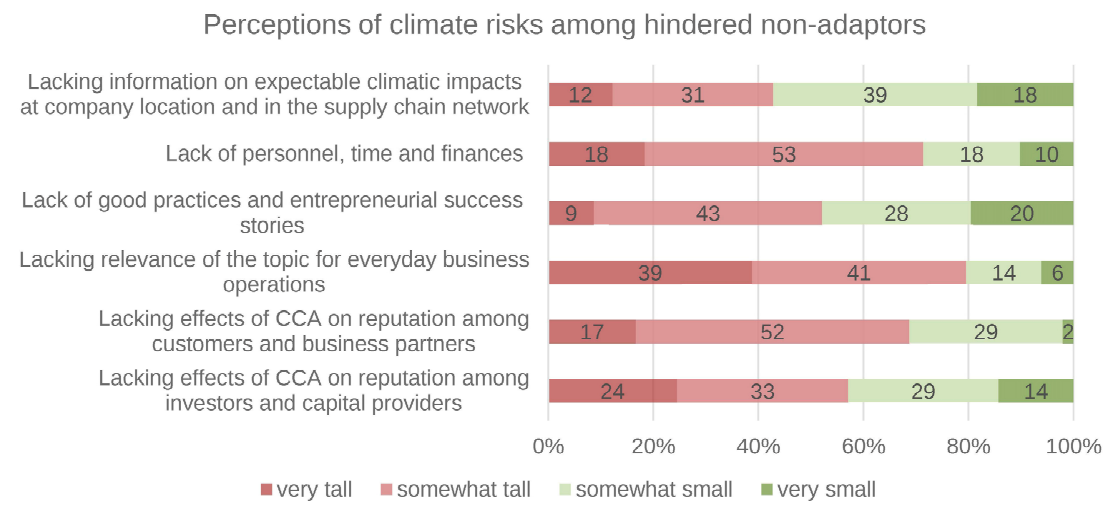

Figure 4. Perceptions of barriers among hindered non-adaptors $(n=49)$.

The fact that respondents out of own impetus did not mention further barriers might be ascribed to the lack of strategic attention non-adaptors per definition pay to adaptation issues. However, various additional barriers emerged in interviews. Thus, based on impulses given by the authors by mentioning climate risks for supply chain networks, interviewees pointed to various barriers they would face if attempting to adapt. Thus, five respective 'latent' barriers (LB) could be identified in interviews:

- LB 1: Dependencies in supply chain networks were considered as a barrier out of various reasons. Thus, interviewees referred to dependencies on strategic choices of more powerful firms (e.g., dependencies on a customer's product strategies). Particularly small firms also pointed to lacking influence on their suppliers' risk management as a further barrier.

- LB 2: Furthermore, highly competitive market environments were considered as a barrier for allocating resources to the management of long-term (climatic and non-climatic) risks.

- LB 3: Shareholder expectations were similarly conceived as a barrier to long-term risk management.

- LB 4: Interviewees moreover pointed to restrictive consequences of small firm size for specific adaptation strategies (e.g., small production volumes inducing restrictions for supplier diversification).

- LB 5: Finally, a legislative barrier was mentioned by an interviewee, who especially referred to additional accounting and judicial requirements if internationally diversifying supplier regions.

\subsubsection{Motivational Factors}

Regarding motivational factors (MF), four major causes of non-adaptive behavior emerged, which differed regarding the frequency of their expression by interviewees. Thus, behavioral beliefs (i.e., either MF 1 or MF 2 depicted below) emerged in statements of all interviewees. In contrast, control beliefs (MF 3) and normative beliefs (MF 4) were only expressed by some interviewees. Consequently, the hypothesis emerges that behavioral beliefs demotivate strategic adaptations irrespectively of the sectoral affiliations of firms interviewees belonged to, whereas the occurrence of demotivating normative and control beliefs presumably depends sectoral affiliation or on other background factors (see Section 3).

\section{- MF 1: Expectations of Insufficient Adaptation Benefits}

As a first behavioral belief, expectations of insufficient benefits linked to strategic adaptations were expressed by various interviewees. In this sense, several interviewees ascribed a generally low 
economic importance to strategic adaptations. Respective statements either suggested that impacts of climate change were only expected to influence business in (distant) future, or that a lack of negative past experiences was extrapolated to the future:

'These things rarely happen. We have never suffered from transport interruptions, a supplier drop-out or power outages [i.e., climatically reinforced risks mentioned by the authors in interviews] during the last ten years. Therefore, incorporating these risks in our strategy is not relevant as the probability of these things is very low.' (Metal processing company)

Moreover, various interviewees considered strategic adaptations as superfluous because they expected climate change to entail automatically occurring, positive impacts on their business. For example, extended working seasons were expected as an advantage by representatives of construction companies. Moreover, several interviewees expected increasing sales of already produced, environmentally friendly products. Even climate risks were in one case associated with automatically occurring benefits:

'If [due to climate change and subsequent decreases in agricultural yields; annotation of the authors] prices for renewable raw materials increase, this would be somewhat advantageous for the company, because the production of the PE-foils is based on mineral oil.' (Packaging manufacturer)

\section{- $\quad$ MF 2: Perceived Uncertainty of Adaptation Benefits}

Perceived uncertainty of adaptation benefits emerged as a second demotivating behavioral belief. Thus, several statements revealed concerns that efforts to adapt might turn into sunk costs or might induce economic disadvantage. In this sense, interviewees first pointed to uncertain developments of framework conditions in the political and market environment (e.g., persistence of funding schemes, developments on world markets) and to subsequently uncertain consequences of present adaptations, such as changes in product lines. Second, statements revealed that uncertain impacts of climate change on the supply chain, for example on supply security, similarly induced perceptions of uncertain adaptation benefits. Third, respective uncertainty was apparently nurtured by doubts about the trustworthiness of climate debates. In this sense, interviewees pointed to contrasting information from natural sciences and to contradictory media reports:

'I really have problems in judging it. What I perceive is that there are scientists who have another perspective on it all [i.e., on the phenomenon of climate change; annotation of the authors] and that also experts have differing opinion.' (Timber construction company)

- $\quad$ MF 3: Perceptions of Low Behavioral Control Regarding Strategic Adaptations

Furthermore, several statements suggest that a perceived lack of behavioral control similarly demotivates strategic adaptations. In interviews, such demotivating control beliefs emerged either as a consequence of barriers (see Section 6.1.3 regarding interactions of barriers and control beliefs) or due to feelings of helplessness associated with natural hazards:

'I can't do anything against it anyway. If a debris flow or inundations occurs in the valley and I have got a construction site there, I will simply not get there.' (Construction company)

- $\quad$ MF 4: Negative Normative Evaluations of Strategic Adaptations

Negative normative evaluations of strategic adaptations only emerged in one statement of an interviewee who expressed a negative judgement of adapting business operations to other than market developments:

‘Energy savings and risk reductions are addressed constantly. Drivers are primarily economic reasons. These are later used in order to satisfy regulatory demands. But the trigger for change are economic considerations.' (Engineering company) 


\subsubsection{Interactions of Barriers and Motivational Factors}

Two types of interactions (I) between barriers and motivational factors emerged: first, influences of barriers on the content of a specific motivational factor (see I 1 depicted below) and second interactions, which influence the actual effects which barriers and motivational factors have on adaptive behavior (I 2 and I 3).

\section{- I: Influences of Barriers on the Content of Control Beliefs}

Influences of barriers on the content of control beliefs repeatedly emerged in interviews. Respective statements suggest that barriers, such as lacking information or low power positions in the supply chain, influence how the capability to successfully conduct strategic adaptations is perceived:

'We are a third-tier supplier. Our customers are supplying automobile companies. This means there will be massive changes in the next years for example regarding e-mobility and it's not assessable if we will be asked for as suppliers then. But there we can only adapt to what the automobile companies define as strategies, we cannot influence them. That means, we are the small fish who delivers what others need.' (Metal processing company)

\section{- I 2: Decreasing Influence of Barriers on the Effects of Motivational Factors}

In line with assumptions of the 'logical action discourse' [35] that actors are motivated, yet abstain from adaptations due to barriers, interviews provided evidence for the influence barriers exert on the effects of motivational factors. Thus, several statements expressed that motivation to adapt existed, for example, due to expected opportunities to reduce supply risks or to extend the company's network. However, this respective motivation did not translate into action due to barriers. The following quote provides one example:

'Supply risks [related to climate change; annotation of the authors] are conceivable. Yet, we so far do not diversify our supplier regions because of additionally required efforts: legislative framework conditions are different, accounting becomes more complex [...].' (Engineering company)

\section{- I 3: Amplifying Influence of Low Motivation on the Effects of Barriers}

Vice versa, interview statements also demonstrated that low motivation can amplify the effects of barriers. Thus, statements suggested that perceptions of lacking benefits of adaptations can increase the effects of barriers, such as lacking resources respectively highly competitive market environments. One quote again illustrates this interaction:

'Price pressure has increased as in our sector, the trend is going away from high-quality to cheap products. Thus, our capacity for topics to play around with has diminished.'

(Telecommunications supplier)

\subsection{Causes of Non-Adaptive Behavior among 'Indifferent Non-Adaptors'}

In the sample, 16 firms (16\% of all survey respondents) matched the criteria of 'indifferent non-adaptors'. Causes of non-adaptive behavior in this group are depicted below and are compared to respective causes in the class of 'hindered non-adaptors' in Table 5.

\subsubsection{Perceived Barriers}

By definition, actors belonging to the class of 'indifferent non-adaptors' didn't perceive any surveyed barriers as relevant. Moreover, no additional barriers were mentioned in interviews by interviewees from this group either. However, it happened that only in an interview a barrier (i.e., lacking information about profitable good practices) was mentioned, which the interviewee formerly had not evaluated as relevant in the survey. 


\subsubsection{Motivational Factors}

Motivational causes of non-adaptive behavior emerging in the group of 'indifferent non-adaptors' could be subsumed under three aspects. Similar to the group of 'hindered non-adaptors', behavioral beliefs (see MF 1 below) emerged as a demotivating factor in statements of all interviewees. In contrast, normative beliefs (MF 2) and control beliefs (MF 3) were again only expressed by some interviewees. Thus, the hypotheses mentioned in Section 6.1.2 is supported that sectoral affiliation or other background factors influence normative and control beliefs, but not, or only to a lesser extent, behavioral beliefs.

\section{- $\quad$ MF 1: Perceptions of insufficient and insecure benefits of strategic adaptations}

Similar to the previously examined group, all interviewees from the group of 'indifferent non-adaptors' expressed perceptions of either insufficient or insecure benefits linked to strategic adaptations. Moreover, similar underlying aspects were mentioned: a general lack of perceived economic benefits, expectations of automatically occurring, positive impacts of climate change on business success, and doubts about the existence of critical climate risks.

\section{- $\quad$ MF 2: Negative normative evaluations of strategic adaptations}

In the group of 'indifferent non-adaptors', negative normative evaluations of strategic adaptations were again scarcely expressed. Respective statements referred either to negative judgements of adapting business operations to other than market demands, or to evaluations of climatically induced action as being naïve due to perceived untruthfulness of climate debates:

'Well, climate change, in which I personally don't believe, is a medially exaggerated topic [ ... ] There are scientists who have changed their minds since the debate began [ ... That is no motivation for me. Motivation for me is to keep the company failure-safe anyway.' (Producer of consumer products)

\section{- MF 3: High presumed control to successfully adapt in future 'if required'}

Regarding control beliefs, no single statement from the group of 'indifferent non-adaptors' expressed perceptions of low control as a demotivating factor. This result may be interpreted as a consequence of the prevailing lack of perceived barriers. However, opposite perceptions of strong behavioral control repeatedly emerged as a demotivating factor. Contrasting assumptions that perceptions of high behavioral control increase motivation [17], several interviewed 'indifferent non-adaptors' expressed demotivation to strategically adapt due to high confidence to successfully adapt in future 'if required':

'If climate change induces impacts on this or that, we will still have enough time to react. I don't need to solve this in advance. With a small company like ours I can react relatively quickly. A global player has to take account of these things and evaluate them in his strategy. As a small company we are flexible enough to adapt to respective circumstances.' (Metal processing company)

\subsubsection{Interactions of Barriers and Motivational Factors}

Corresponding to only exceptionally occurring perceptions of barriers, no interaction of barriers and motivational factors emerged in statements of 'indifferent non-adaptors'.

\section{Discussion}

Table 5 summarizes the results of the survey and of interviews. By standardizing the results to a nominal scale, Table 5 shows which factors were perceived as relevant by firm managers from 
the different classes of non-adaptors. Notwithstanding the fact that further causes of non-adaptive behavior as well as further interactions may be revealed if extending the number of interviews, the depicted results enable initial insights:

First, Table 5 provides evidence for the importance of motivational factors as causes of non-adaptive behavior. Thus, Table 5 shows that among examined indifferent non-adaptors, motivational factors nearly alone caused non-adaptive behavior. Consequently, in contrast to assumptions of the 'logical action discourse' [35], removing barriers might hardly induce strategic adaptations in this group of non-adaptors.

Vice versa, regarding hindered non-adaptors, case study results don't allow to recognize a dominance of either motivational factors or barriers as causes of non-adaptive behavior. However, Table 5 demonstrates that various motivational factors play a role among hindered non-adaptors and that removing barriers may thus only suffice to initiate strategic adaptations in some firms of this group.

Moreover, the study has provided empirical evidence for the existence of interactions between barriers and motivational factors and thus underlines demands from conceptual discussions to conceive barriers as contingent factors, and not as static entities [15]. In addition to the interactions suggested in the reasoned action approach $[17,18]$, the existence of one further interaction (i.e., influences of motivational factors on the effects of barriers) could be empirically demonstrated.

Finally, study results suggest that the occurrence of demotivating factors, particularly of demotivating control and normative beliefs, depends on background factors. In particular, sectoral affiliation emerged as a potentially relevant background factor. However, other background factors that were not considered within the scope of the present study might also play a role: for example, personal characteristics of managers, such as general attitudes or values; firm attributes, such as size, innovation culture or ownership structures; or informational background factors, such as accessible sources of information and media reporting.

The following limitations might have influenced the obtained results. First, additional causes of non-adaptive behavior may be revealed if extending the number of interviews. Furthermore, results on causes of non-adaptive behavior may turn out differently if changing to a less (or more) climate-sensitive region, if changing the cultural or socioeconomic context, or if examining other sectors. Additionally, other results may emerge if focusing on other types of managers (e.g., on environmental managers or risk managers). Apart from methodological limitations, the chosen analytical focus on the psychological level limits the possible scope of identifiable causes of lacking strategic adaptations in firms. Thus, other aspects may be revealed if concentrating on the firm level (e.g., on corporate decision-making processes) $[40,41]$ or on actor networks and actor constellations in the economic and political environment of firms. 
Table 5. Causes of non-adaptive behavior across classes of non-adaptors: summary and condensation of results.

\begin{tabular}{|c|c|c|c|c|}
\hline & HNA & INA & Causes of Non-Adaptive Behavior Emerging in the Case Study & Condensed Causes \\
\hline \multirow{9}{*}{ Barriers } & $\square$ & $\square$ & Lacking information about expectable climatic impacts on firm location and supply chain & \multirow[t]{3}{*}{ Lacking resources } \\
\hline & $\square$ & $\square$ & Lacking information about good practices & \\
\hline & $\square$ & $\square$ & Lack of personnel, time and finances & \\
\hline & $\square$ & $\square$ & Lacking capabilities of specific adaptations due to consequences of small firm size ${ }^{*}$ & \multirow[t]{2}{*}{ Lacking capabilities } \\
\hline & $\square$ & $\square$ & Restrained capability of long-term risk management due to shareholder expectations * & \\
\hline & $\square$ & $\square$ & Restricted opportunities to strategically adapt due to low power position in the supply chain* & \multirow{2}{*}{$\begin{array}{l}\text { Hindering actor constellations in } \\
\text { the supply chain }\end{array}$} \\
\hline & $\square$ & $\square$ & Lacking influence on the risk management conducted by suppliers* & \\
\hline & $\square$ & $\square$ & Lacking economic impacts (e.g., reputational gains) of strategic adaptations & \multirow{2}{*}{$\begin{array}{l}\text { Hindering economic and political } \\
\text { framework conditions }\end{array}$} \\
\hline & $\square$ & $\square$ & Highly competitive market environments * & \\
\hline \multirow{8}{*}{ Motivational factors } & $\square$ & $\square$ & Perceptions of generally lacking economic relevance of adaptations & \multirow[t]{2}{*}{ Expectations of insufficient benefits } \\
\hline & $\square$ & $\square$ & Expectation of automatically occurring, positive impacts of climate change & \\
\hline & $\square$ & $\square$ & Perceived uncertainty of benefits due to the uncertain development of framework conditions & \multirow[t]{3}{*}{ Perceived uncertainty of benefits } \\
\hline & $\square$ & $\square$ & Perceived uncertainty of benefits due to uncertain impacts of climate change & \\
\hline & $\square$ & $\square$ & Perceived uncertainty of benefits due to doubts about the trustworthiness of climate debates & \\
\hline & $\square$ & $\square$ & Resignation due to weak control beliefs & \multirow[t]{2}{*}{ Weak or strong control beliefs } \\
\hline & $\square$ & $\square$ & High confidence to successfully adapt in future, if required & \\
\hline & $\square$ & $\square$ & Evaluations of adaptations as naïve due to perceived untruthfulness of climate debate & $\begin{array}{l}\text { Negative normative evaluations of } \\
\text { strategic adaptations }\end{array}$ \\
\hline \multirow{3}{*}{ Interactions } & $\square$ & $\square$ & Influences of barriers on the content of control beliefs & \multirow{3}{*}{$\begin{array}{l}\text { Interactions between barriers and } \\
\text { motivational factors influencing } \\
\text { their content and effects }\end{array}$} \\
\hline & $\square$ & $\square$ & Decreasing influence of barriers on the effects of motivational factors & \\
\hline & $\square$ & $\square$ & Amplifying influences of lowly developed motivational factors on the effects of barriers & \\
\hline
\end{tabular}

$\square / \square$ is Aspect referred to/not referred to as cause of non-adaptive behavior; HNA/INA is Hindered non-adaptors/Indifferent non-adaptors; * Barrier emerged in interviews only. 


\section{Conclusions}

The study has provided first insights how a behavioral perspective can be introduced into adaptation research. The reasoned action approach thereby proved suitable for analyzing non-adaptive behavior among firm managers, particularly if adding slight variations (see Section 3). Based on a comparison of different classes of non-adaptors, various barriers, motivational factors and interactions between them were identified.

Thus, obtained results contrast implicit assumptions of the 'logical action discourse' [35] that the behavior of managers will likely change if barriers are removed. Instead, findings that non-adaptive behavior is not necessarily connected to perceptions of barriers underline the need to pay additional attention to motivational factors. Finally, results on interactions and first suggestions about background factors point to a changeable nature of the identified causes of non-adaptive behavior.

Based on the obtained results, subsequent studies may focus on prerequisites of behavioral change by investigating background factors and the identified interactions in more detail. Additionally, the relative influence of the identified causes of non-adaptive behavior may be assessed in quantitative terms. Furthermore, changing the comparative perspective (e.g., by comparing sectors) may reveal additional and more differentiated insights into the causality of non-adaptive behavior. Finally, action-theoretical analyses might be employed as an alternative actor-centered lens in order to generate complementary insights into causes of lacking strategic adaptation in firms.

Acknowledgments: This work was conducted within the project adapt $X$ which is supported by the COMET funding program of the Austrian Ministry for Transport, Innovation and Technology, the Austrian Ministry of Science, Research and Economy, the state of Tyrol, and the state Vorarlberg; the COMET program is processed by the Austrian Research Promotion Agency (FFG). Moreover, the work was promoted by the University of Innsbruck within the scope of a doctoral scholarship. Furthermore, organizational support of the Tyrolean Chamber of Commerce was crucially enabling the firm survey. Finally, the authors would like to thank Ralf Schüle, Wuppertal Institute for Climate, Environment and Energy for helpful comments and discussions.

Author Contributions: Ulrike Meinel conceptualized and wrote the study and conducted the firm survey as well as the interviews. Karl-Michael Höferl supported the study regarding its methodological foundations in comparative methodology and qualitative content analysis.

Conflicts of Interest: The authors declare no conflicts of interest.

\section{Appendix A}

The following differences may be noted between the employed model of non-adaptive behavior (Figure 1) and the model developed by Fishbein and Ajzen in the reasoned action approach [17]:

- Due to the focus on inaction in the present study, the authors employ the concept of barriers instead of the term 'actual control' which in the original model is used referring to barriers and to supportive outside factors.

- A stronger focus is laid on interactions between barriers and motivational factors compared to the model of Fishbein and Ajzen [17].

- Whereas in the reasoned action approach, also interactions between the different motivational factors are described, the present study doesn't systematically analyze these aspects and therefore does not depict them in the employed model (Figure 1).

\section{Appendix B}

The segmentation of (non-)adaptors (see Figure 2) was conducted based on surveyed data on perceptions of barriers and on the actual implementation of strategic adaptations.

When operationalizing strategic adaptations, the authors focused on the integration of adaptation issues in different strategic management domains thereby employing corporate decisions of firms as a proxy for managers' behavior (see Section 4). Table A1 depicts how the implementation of strategic adaptations was operationalized in the survey. 
In order to identify respondents belonging to the different classes of non-adaptors, in a first step, all 'non-adaptors' (see Figure 2) were identified. For this purpose, all respondents were selected who had indicated that in their firms none of the queried aspects of strategic adaptation had been implemented (based on the criteria displayed in Table A1). Non-adaptors identified in this way were, in a second step, differentiated based on their perceptions of barriers. Thus, identified non-adaptors who had simultaneously indicated to perceive all barriers as irrelevant (i.e., as 'somewhat small' or 'very small') were considered as 'indifferent non-adaptors'. Vice versa, respective respondents were conceived as 'hindered non-adaptors' if they had indicated to perceive at least one barrier as relevant (i.e., as 'somewhat tall' or 'very tall').

Table A1. Implementation of strategic adaptations-operationalization in the survey.

\begin{tabular}{lll}
\hline Question in the Survey & Response Categories & $\begin{array}{l}\text { Coding of } \\
\text { Response Categories }\end{array}$ \\
\hline \multirow{3}{*}{$\begin{array}{l}\text { Is the topic of climate change } \\
\text { adaptation formally associated to a } \\
\text { management system and if yes } \\
\text { to which? }\end{array}$} & $\begin{array}{l}\text { 'sustainability-/environmental management' or } \\
\text { 'risk management' or 'other management } \\
\text { system: }\end{array}$ & implementation \\
\cline { 2 - 3 } & 'no association to existing management system' & no implementation \\
\cline { 2 - 3 } & $\begin{array}{l}\text { 'no respective management systems exists (e.g., } \\
\text { due to too small firm size)' }\end{array}$ & no implementation \\
\hline $\begin{array}{l}\text { How are the consequences of climate } \\
\text { change handled by firm executives? }\end{array}$ & $\begin{array}{l}\text { 'not communicated' or 'communicated as a } \\
\text { marginal issue' }\end{array}$ & no implementation \\
\cline { 2 - 3 } & 'regularly raised as an issue' or 'communicated & implementation \\
\hline $\begin{array}{l}\text { Which role do opportunities and risks } \\
\text { related to climate change play in } \\
\text { processes of strategic foresight }\end{array}$ & 'somewhat important' or 'very important' & implementation \\
\cline { 2 - 3 } & 'none' or 'somewhat marginal' & no implementation \\
\cline { 2 - 3 } & 'no strategic foresight conducted' & no implementation \\
\hline
\end{tabular}

\section{References}

1. Linnenluecke, M.K.; Griffiths, A.; Winn, M.I. Firm and industry adaptation to climate change: A review of climate adaptation studies in the business and management field. Wiley Interdiscip. Rev. Chang. 2013, 4, 397-416. [CrossRef]

2. Linnenluecke, M.K.; Griffiths, A.; Winn, M. Extreme weather events and the critical importance of anticipatory adaptation and organizational resilience in responding to impacts. Bus. Strateg. Environ. 2012, 21, 17-32. [CrossRef]

3. Meinel, U.; Abegg, B. A multi-level perspective on climate risks and drivers of entrepreneurial robustness-Findings from sectoral comparison in alpine Austria. Glob. Environ. Chang. 2017, 44, 68-82. [CrossRef]

4. Winn, M.; Kirchgeorg, M.; Griffiths, A.; Linnenluecke, M.K.; Günther, E. Impacts from climate change on organizations: A conceptual foundation. Bus. Strateg. Environ. 2011, 20, 157-173. [CrossRef]

5. Lockamy, A. Assessing disaster risks in supply chains. Ind. Manag. Data Syst. 2014, 114, 755-777. [CrossRef]

6. UK Environment Agency. Assessing and Managing Climate Change Risks in Supply Chains; Environment Agency: Bristol, UK, 2013.

7. Stechemesser, K.; Endrikat, J.; Grasshoff, N.; Guenther, E. Insurance companies' responses to climate change: Adaptation, dynamic capabilities and competitive advantage. Geneva Pap. Risk Insur. Issues Pract. 2015, 40, 557-584. [CrossRef]

8. Crawford, M.; Seidel, S. Weathering the Storm: Building Business Resilience to Climate Change. 2013. Available online: https://www.c2es.org/publications/weathering-storm-building-business-resilienceclimate-change (accessed on 20 April 2017).

9. Loechel, B.; Hodgkinson, J.; Moffat, K. Climate change adaptation in Australian mining communities: Comparing mining company and local government views and activities. Clim. Chang. 2013, 119, 465-477. [CrossRef] 
10. Grüneis, H.; Penker, M.; Höferl, K.-M. The full spectrum of climate change adaptation: Testing an analytical framework in Tyrolean mountain agriculture (Austria). Springerplus 2016, 5, 1848. [CrossRef] [PubMed]

11. Hopkins, D. The sustainability of climate change adaptation strategies in New Zealand's ski industry: A range of stakeholder perceptions. J. Sustain. Tour. 2014, 22, 107-126. [CrossRef]

12. Intergovernmental Panel on Climate Change (IPCC). Climate Change 2007: Impacts, Adaptation and Vulnerability; Contribution of Working Group II to the Fourth Assessment Report of the Intergovernmental Panel on Climate Change; Cambridge University Press: Cambridge, UK, 2007.

13. Berkhout, F. Adaptation to climate change by organizations. Wiley Interdiscip. Rev. Clim. Chang. 2011, 3, 91-106. [CrossRef]

14. Biesbroek, G.R.; Termeer, C.J.A.M.; Klostermann, J.E.M.; Kabat, P. Analytical lenses on barriers in the governance of climate change adaptation. Mitig. Adapt. Strateg. Glob. Chang. 2014, 19, 1011-1032. [CrossRef]

15. Biesbroek, G.R.; Klostermann, J.E.M.; Termeer, C.J.A.M.; Kabat, P. On the nature of barriers to climate change adaptation. Reg. Environ. Chang. 2013, 13, 1119-1129. [CrossRef]

16. Biesbroek, G.R.; Termeer, C.J.A.M.; Klostermann, J.E.M.; Kabat, P. Rethinking barriers to adaptation: Mechanism-based explanation of impasses in the governance of an innovative adaptation measure. Glob. Environ. Chang. 2014, 26, 108-118. [CrossRef]

17. Fishbein, M.; Ajzen, I. Predicting and Changing Behaviour: The Reasoned Action Approach; Psychology Press: Haven, NY, USA, 2010.

18. Ajzen, I. The theory of planned behavior. Organ. Behav. Hum. Decis. Process. 1991, 50, 179-211. [CrossRef]

19. Agrawala, S.; Carraro, M.; Kingsmill, N.; Lanzi, E.; Mullan, M.; Prudent-Richard, G. Private Sector Engagement in Adaptation to Climate Change; OECD Publishing: Paris, France, 2011.

20. Lühr, O.; Kramer, J.-P.; Lambert, J.; Kind, C.; Savelsberg, J. Analyse Spezifischer Risiken des Klimawandels und Erarbeitung von Handlungsempfehlungen Für Exponierte Industrielle Produktion in Deutschland. Studie im Auftrag des Bundesministeriums Für Wirtschaft und Energie; Federal Ministry for Economic Affairs and Energy: Berlin, Germany, 2014.

21. Allianz Global Corporate and Specialty. Managing Disruptions. Supply Chain Risk: An Insurer's Perspective; Allianz Global Corporate and Specialty: Munich, Germany, 2012.

22. Fichter, K.; Schneider, T. Wie Unternehmen den Folgen des Klimawandels Begegnen: Ergebnisse der Panelbefragung 2010 und 2012. Nordwest2050-Werkstattbericht (No. 24); Universität Oldenburg: Oldenburg, Germany, 2013.

23. Chemical Industries Association; Non-Ferrous Alliance; Climate Ready. Safeguarding Chemical Business in Changing Climate. How to Prepare a Climate Change Adaptation Plan. Available online: http:/ /www.chemical. org.uk/regulatoryissues/environmental/safeguardingchemicalbusinessesinachangingcli.aspx (accessed on 26 June 2017).

24. Fleming, A.; Hobday, A.J.; Farmery, A.; van Putten, E.I.; Pecl, G.T.; Green, B.S.; Lim-Camacho, L. Climate change risks and adaptation options across Australian seafood supply chains-A preliminary assessment. Clim. Risk Manag. 2014, 1, 39-50. [CrossRef]

25. Ford, J.D.; Pearce, T.; Prno, J.; Duerden, F.; Ford, L.B.; Beaumier, M.; Smith, T. Perceptions of climate change risks in primary resource use industries: A survey of the Canadian mining sector. Reg. Environ. Chang. 2010, 10, 65-81. [CrossRef]

26. Onischka, M.; Liedtke, C.; Jordan, N.D. How to sensitize the financial industry to resource efficiency considerations and climate change related risks. J. Environ. Assess. Policy Manag. 2012, 14, 1250017. [CrossRef]

27. Vogus, T.J.; Sutcliffe, K.M. Organizational resilience: Towards a theory and research agenda. In Proceedings of the IEEE Conference, Montreal, QC, Canada, 7-10 October 2007.

28. Busch, T. Organizational adaptation to disruptions in the natural environment: The case of climate change. Scand. J. Manag. 2011, 27, 389-404. [CrossRef]

29. Adger, W.N.; Arnell, N.W.; Tompkins, E.L. Successful adaptation to climate change across scales. Glob. Environ. Chang. 2005, 15, 77-86. [CrossRef]

30. Gunderson, L.H.; Holling, C.S. Panarchy: Understanding Transformations in Human and Natural Systems; Island Press: Washington, DC, USA, 2002.

31. Stokols, D.; Lejano, R.P.; Hipp, J. Enhancing the Resilience of Human-Environment Systems: A Social Ecological Perspective. Ecol. Soc. 2013, 18. [CrossRef] 
32. Anderies, J.M.; Janssen, M.A. The fragility of robust social-ecological systems. Glob. Environ. Chang. 2011, 21, 1153-1156. [CrossRef]

33. Gottschick, M. How stakeholders handle uncertainty in a local climate adaptation governance network. Clim. Chang. 2015, 132, 445-457. [CrossRef]

34. Gifford, R.; Comeau, L.A. Message framing influences perceived climate change competence, engagement, and behavioral intentions. Glob. Environ. Chang. Policy Dimens. 2011, 21, 1301-1307. [CrossRef]

35. Fleming, A.; Vanclay, F.; Hiller, C.; Wilson, S. Challenging dominant discourses of climate change. Clim. Chang. 2014, 127, 407-418. [CrossRef]

36. Gifford, R. The dragons of inaction. Am. Psychol. 2011, 66, 290-302. [CrossRef] [PubMed]

37. Feng, X.; Liu, M.; Huo, X.; Ma, W. What motivates farmers' adaptation to climate change? The case of apple farmers of Shaanxi in China. Sustainability 2017, 9. [CrossRef]

38. Serenari, C.; Leung, Y.-F.; Attarian, A.; Franck, C. Understanding environmentally significant behavior among whitewater rafting and trekking guides in the Garhwal Himalaya, India. J. Sustain. Tour. 2012, 20, 757-772. [CrossRef]

39. Koger, S.M.; Winter, D.D.N. Psychology for Sustainability: The Psychology of Environmental Problems, 3rd ed.; Psychology Press: New York, NY, USA; London, UK, 2010.

40. Cyert, R.M.; March, J.G. A Behavioral Theory of the Firm. 1963. Available online: https: / /books.google.com.hk/books?hl=zh-TW\&lr=\&id=qqZ_FDFoDcMC\&oi=fnd\&pg=PA60\&dq=A+ behavioral+theory+of+the+firm\&ots=9V5ORgBs5P\&sig=Y-WdyxAqH6ZhoQbcsFr5FQBPaag\&redir_esc= $\mathrm{y} \# \mathrm{v}=$ onepage\&q=A \%20behavioral\%20theory\%20of\%20the \%20firm\&f=false (accessed on 22 June 2017).

41. Gavetti, G.; Greve, H.R.; Levinthal, D.A.; Ocasio, W. The Behavioral Theory of the Firm: Assessment and Prospects. Acad. Manag. Ann. 2012, 6, 1-40. [CrossRef]

42. Bertrand, M.; Schoar, A. Managing with Style: The Effect of Managers on Firm Policies. Q. J. Econ. 2003, 118, 1169-1208. [CrossRef]

43. Gobiet, A.; Kotlarski, S.; Beniston, M.; Heinrich, G.; Rajczak, J.; Stoffel, M. 21st century climate change in the European Alps-A review. Sci Total Env. 2014, 493, 1138-1151. [CrossRef] [PubMed]

44. Keiler, M.; Knight, J.; Harrison, S. Climate change and geomorphological hazards in the Eastern European Alps. Philos. Trans. R. Soc. A Math. Phys. Eng. Sci. 2010, 368, 2461-2479. [CrossRef] [PubMed]

45. Baruch, Y.; Holtom, B.C. Survey response rate levels and trends in organizational research. Hum. Relat. 2008, 61, 1139-1160. [CrossRef]

46. Tyrolean Chamber of Commerce. Beschäftigtenstatistik 2014. Dienstgeberbetriebe, Beschäftigte und EPU in der gewerblichen Wirtschaft Tirols; Tyrolean Chamber of Commerce: Innsbruck, Austria, 2014.

47. Woodside, A.G.; Martin, D. Tourism Management: Analysis, Behaviour and Strategy; CABI: Oxfordshire, UK, 2007.

48. Tyrolean Chamber of Commerce. Unselbständig Beschäftigte Juli 2016-Nach Fachverbänden, Größenklassen, Stellung im Unternehmen und Geschlecht. Available online: http://wko.at/statistik/ extranet/BeschStat/AT201607_FG_GK_BSI.pdf (accessed on 22 March 2017).

49. Fudge, S.; Peters, M. Behaviour change in the UK climate debate: An assessment of responsibility, agency and political dimensions. Sustainability 2011, 3, 789-808. [CrossRef]

50. Tompkins, E.L.; Eakin, H. Managing private and public adaptation to climate change. Glob. Environ. Chang. 2012, 22, 3-11. [CrossRef]

(C) 2017 by the authors. Licensee MDPI, Basel, Switzerland. This article is an open access article distributed under the terms and conditions of the Creative Commons Attribution (CC BY) license (http:/ / creativecommons.org/licenses/by/4.0/). 